Irena Dul

Jacek Senkara

Mariusz Bober

Jerzy Jakubowski

\title{
Wpływ wysokotemperaturowego wygrzewania próżniowego na lutowność Inconelu 718 lutem Palnicro 36
}

\section{The effect of high-temperature vacuum annealing on the brazeability of Inconel 718 by Palnicro 36 brazing filler metal}

\section{Streszczenie}

Lutowanie twarde Inconelu 718 jest utrudnione ze względu na zawartość w materiale dodatków stopowych o wysokim powinowactwie do tlenu. Ponadto w praktyce przemysłowej detale przed lutowaniem przechodzą szereg operacji technologicznych w podwyższonej temperaturze w próżni. Celem pracy było zbadanie, jaki wpływ mają procesy wyżarzania próżniowego na lutowność Inconelu 718 lutem Palnicro 36.

Badano zwilżalność i rozpływność ciekłego lutu na powierzchni materiału wyżarzanego uprzednio w próżni w różnych warunkach czasu i temperatury, a także mikrostrukturę złączy lutowanych. Ustalono, iż lutowność Inconelu 718 lutem Palnicro 36 pogarsza się ze wzrostem temperatury uprzedniego wyżarzania w próżni.

\section{Wstęp}

Ze względu na swoje korzystne właściwości stopy niklu, a wśród nich Inconel 718 , znalazły ważne zastosowanie w budowie silników lotniczych. Przetwarzanie tych stopów (cięcie, obróbka plastyczna różnymi metodami, wyżarzanie międzyoperacyjne, obróbka cieplna, spawanie, zgrzewanie, lutowanie, modyfikacja powierzchni) jest powszechne w przemyśle lotniczym. Każdy z wymienionych procesów ma swoją specyfikę wynikającą zarówno $z$ właściwości materiałów, jak i konieczności spełnienia odpowiednich wymogów [1].

Dr inż. Irena Dul - WSK PZL Rzeszów, prof. dr hab. inż. Jacek Senkara, dr inż. Mariusz Bober, dr inż. Jerzy Jakubowski - Politechnika Warszawska.

\section{Abstract}

Brazing of Inconel 718 is difficult due to the presence of alloying material with high affinity for oxygen. Moreover, in commercial practice, the machine parts before brazing pass a number of technological operations at elevated temperature in vacuum. The aim of this study was to investigate the effect of vacuum annealing processes of Inconel 718 on the brazeability of Palnicro 36 brazing filler metal.

The wetting and spreading of the liquid brazing filler metal were studied on the surface of the material previously annealed in vacuum at different conditions of time and temperature, and the structure of brazed joints. It was found that the brazeability of Inconel 718 by Palnicro 36 brazing filler metal deteriorates with increasing the previous annealing temperature in the vacuum.

Jednym z podstawowych procesów spajania stopów Ni jest lutowanie twarde i lutowanie wysokotemperaturowe w piecach próżniowych. Obejmuje ono nie tylko sam proces łączenia, ale także ciąg innych, powiązanych ze sobą operacji: przygotowania powierzchni, montażu i pozycjonowania zespołów. Przygotowanie powierzchni może polegać na myciu, a niekiedy obróbce strumieniowo-ściernej i/lub zastosowaniu powłok technologicznych (np. niklu galwanicznego). Niejednokrotnie lutuje się zespoły składające się z kilkudziesięciu różnych detali, dla których występuje znaczna różnica przekrojów pomiędzy blachami i częściami w postaci odlewów lub odkuwek. Takie lutowanie wymaga odpowiedniego dopasowania elementów w celu optymalizacji szerokości szczeliny lutowniczej, a także właściwego przebiegu czasowo-temperaturowego, aby nastąpiło wyrównanie temperatury poszczególnych przekrojów. Lutami 
stosowanymi w lotnictwie dla stopów niklu są BNi2, BNi3, Palnicro 36, a także luty na osnowie srebra i złota

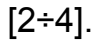

Inconel 718, z uwagi na zawartość składników stopowych o wysokim powinowactwie do tlenu (tabl. I), nie jest materiałem łatwym do lutowania. Trudności spajania Inconelu 718 spowodowały, iż próbowano opracować niekonwencjonalne sposoby jego lutowania, zmierzające do skrócenia czasu oddziaływania kontaktu ciekłego lutu z podłożem (obniżenie tendencji do nadmiernej penetracji w podłoże i jego rozpuszczania w cieczy, a także pęknięć gorących i kruchości złącza). Można tutaj wymienić zastosowanie szybkiego nagrzewania indukcyjnego w osłonie argonu [5], nagrzewania promieniowaniem podczerwonym [8], docisku [9], dodatkowego getterowania próżni [6], czy zastosowania lutowania dyfuzyjnego z zanikającą fazą ciekłą [10]. W dostępnych publikacjach sugeruje się, że proces lutowania powinien odbywać się w wysokiej próżni (jednakże wymieniane są różne jej poziomy: od 0,13 $\mathrm{Pa}$,

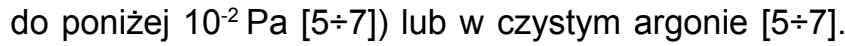
Warunki procesu zależą również od aktywnych składników lutu, takich jak $\mathrm{B}, \mathrm{Cr}$, Si, mogących redukować niektóre tlenki, oraz od zawartości palladu, poprawiającego zwilżalność.

Z drugiej strony, detale wykonane ze stopów niklu mogą przechodzić przed lutowaniem szereg operacji w podwyższonej temperaturze w próżni, nawet kilkugodzinnych. Zachodzą wówczas liczne procesy w warstwie powierzchniowej, zmieniające jej skład chemiczny, strukturę i morfologię w wyniku selektywnego parowania składników, segregacji, reakcji heterogenicznych.

Celem pracy było zbadanie, czy i jaki wpływ mają procesy uprzedniego wyżarzania próżniowego na lutowność Inconelu 718 lutem Palnicro 36.

\section{Charakterystyka materiałów złącza}

\section{Inconel 718}

Inconel 718 to przesycany, a następnie utwardzany wydzieleniowo stop Ni o doskonałej odporności na korozję w wielu mediach. Jest odporny na działanie związków siarki dzięki dodatkowi chromu. Skład chemiczny materiału podano $\mathrm{w}$ tablicy I. Temperatura topnienia Inconelu 718 wynosi $1260 \div 1336^{\circ} \mathrm{C}$, gęstość $8,22 \mathrm{Mg} / \mathrm{m}^{3}$.

Dobre właściwości mechaniczne, odporność na pełzanie, żarowytrzymałość, odporność na korozję, podatność na kucie i odlewanie, stosunkowo dobra spawalność i przystępny koszt powodują, że jest stosowany w silnikach lotniczych np. na elementy turbin, dyski, wały, łopatki kompresora i turbiny, wyloty spalin [12]. Wykazuje dobre właściwości wytrzymałościowe do temperatury $650^{\circ} \mathrm{C}[13,14]$, choć można go stosować jako materiał odporny na utlenianie nawet do temperatury powyżej $1000^{\circ} \mathrm{C}$. Jego właściwości w dużej mierze zależą od umocnienia wydzieleniowego fazą $\gamma$ " $\left(\mathrm{Ni}_{3} \mathrm{Nb}\right)$ podczas utwardzania [15]. Standardowa obróbka cieplna to przesycanie w temperaturze $930 \div 1010^{\circ} \mathrm{C} \mathrm{z}$ szybkim chłodzeniem, następnie utwardzanie w $720^{\circ} \mathrm{C}$ przez $8 \mathrm{~h}$, powolne chłodzenie z prędkością $50^{\circ} \mathrm{C} / \mathrm{h}$ do temp. $620^{\circ} \mathrm{C}$ i wytrzymanie przez kolejne $8 \mathrm{~h}$. Łączny czas utwardzania wynosi ok. $18 \mathrm{~h}$. Wymagana twardość po utwardzaniu wynosi min. $36 \mathrm{HRC}$, a w praktyce osiąga się nawet $44 \mathrm{HRC}$.

\section{Lut Palnicro 36}

Skład chemiczny lutu zamieszczono w tablicy II. Zawiera on znaczne ilości palladu, który poprawia zwilżalność wielu metali i tlenków oraz korzystnie wpływa na plastyczność lutu i jego odporność na korozję. Jego udział powoduje także, iż spoina ma bardzo dobrą odporność na pełzanie w podwyższonej temperaturze, co jest niezwykle istotne dla zastosowania w silniku lotniczym. Lut ma też niezłe właściwości mechaniczne (znacząca zawartość Cr). Optymalizowane zawartości Si i B pozwalają na utrzymanie dobrych właściwości lutowniczych:

- bor zmniejsza napięcie powierzchniowe cieczy, co silnie wpływa na zwilżanie i rozpływność, redukuje niektóre tlenki, ale z drugiej strony zwiększa rozpuszczalność podłoża, segreguje na granicach ziarn i tworzy borki $\mathrm{Cr}_{x} \mathrm{~B}_{y}$, wiążąc $\mathrm{Cr}$ z roztworu stałego i wpływając na kruchość stopu;

- zawartość krzemu wpływa na temperaturę topnienia lutu, redukuje tlenki metali o mniejszym powinowactwie chemicznym do tlenu, a także zwiększa niebezpieczeństwo pęknięć gorących.

Inne właściwości fizyczne lutu Palnicro 36 [16]:

- temperatura likwidus: $960^{\circ} \mathrm{C}$,

- temperatura solidus: $820^{\circ} \mathrm{C}$,

- gęstość: 8,83 Mg/m³,

- zalecana temperatura lutowania: $970 \div 1050^{\circ} \mathrm{C}$,

- zalecana atmosfera lutowania: próżnia $10^{-1} \div 10^{-2} \mathrm{~Pa}$.

Lut Palnicro 36 jest komercyjnie dostępny w postaci folii, proszku lub pasty lutowniczej.

\section{Badania własne lutowności}

W literaturze przedmiotu można spotkać kilka sposobów definiowania lutowności, ich dyskusja została przedstawiona w [17]. W tym przypadku przyjęto

Tablica I. Skład chemiczny Inconelu 718, \% wag. [11]

Table I. Chemical composition of Inconel 718, wt.\% [11]

\begin{tabular}{|c|c|c|c|c|c|c|c|c|c|c|}
\hline C & $\mathrm{Cr}$ & $\mathrm{Mn}$ & Mo & $\mathrm{Si}$ & $\mathrm{P}$ & $\mathrm{Al}$ & $\mathrm{Ti}$ & $\mathrm{Nb}+\mathrm{Ta}$ & $\mathrm{Ni}$ & $\mathrm{Fe}$ \\
\hline $\begin{array}{c}\max . \\
0,08\end{array}$ & $\begin{array}{c}17,0 \\
\div 21,0\end{array}$ & $\begin{array}{c}\max . \\
0,35\end{array}$ & $\begin{array}{c}2,80 \\
\div 3,30\end{array}$ & $\begin{array}{c}\max . \\
0,35\end{array}$ & $\begin{array}{c}\max . \\
0,015\end{array}$ & $\begin{array}{c}0,20 \\
\div 0,80\end{array}$ & $\begin{array}{c}0,65 \\
\div 1,15\end{array}$ & $\begin{array}{c}4,75 \\
\div 5,50\end{array}$ & $\begin{array}{c}50,0 \\
\div 55,0\end{array}$ & reszta \\
\hline
\end{tabular}


Tablica II. Skład chemiczny lutu Palnicro 36, \% wag. [16] Table II. Chemical composition of Palnicro 36 brazing filler metal [16]

\begin{tabular}{|c|c|c|c|c|c|c|}
\hline $\mathrm{Cr}$ & $\mathrm{Fe}$ & $\mathrm{Si}$ & $\mathrm{C}$ & $\mathrm{B}$ & $\mathrm{Pd}$ & $\mathrm{Ni}$ \\
\hline 9,5 & 0,5 & 0,25 & 0,06 & 2,5 & 35 & reszta \\
$\div 1,5$ & max. & $\div 1,0$ & max. & $\div 25$ & $\div 37$ & \\
\hline
\end{tabular}

określenie amerykańskiej normy AWS A3 określającej lutowność jako zdolność materiału lutowanego do utworzenia w danych warunkach określonej struktury oraz spełnienia wymogów zamierzonej eksploatacji. Jako miarę lutowności przyjęto $w$ tym przypadku wyniki laboratoryjnych testów zwilżania, rozpływności w warunkach przemysłowych oraz tworzącą się strukturę złącza lutowanego.

\section{Przygotowanie próbek podłoży}

Inconel $718 \mathrm{w}$ formie blachy cięto na próbki o wymiarach $20 \times 20 \times 0,9 \mathrm{~mm}$ do badań zwilżalności i rozpływności, oraz $20 \times 40 \times 0,9 \mathrm{~mm}$ do wykonania gotowych złączy. Blachę myto w płuczce ultradźwiękowej w standardowych warunkach stosowanych w przemyśle lotniczym, a następnie poddano wyżarzaniu w próżni. Wytypowano takie kombinacje czasu i temperatury, które odpowiadały rzeczywistym operacjom technologicznym w warunkach produkcyjnych. Stosowano następujący cykl grzewczy: odpompowanie do próżni $0,1 \mathrm{~Pa}$ i wytrzymanie w czasie 5 min, grzanie z prędkością $10^{\circ} \mathrm{C} / \mathrm{min}$ do osiągnięcia zadanej temperatury, wytrzymanie $w$ określonym czasie, szybkie chłodzenie $z$ zastosowaniem dmuchawy i argonu o ciśnieniu $2 \cdot 10^{4} \mathrm{~Pa}$. Zastosowano również cykl z wygrzewaniem w podciśnieniu argonu $80 \mathrm{~Pa}$, stosowany niekiedy w przemyśle lotniczym.

Przyjęto następujące warianty:

Czas: $1 \mathrm{~h}$ temperatura: $750^{\circ} \mathrm{C}$

$750^{\circ} \mathrm{C}+\mathrm{Ar}$

$950^{\circ} \mathrm{C}$

$950^{\circ} \mathrm{C}+\mathrm{Ar}$

Czas: $2 \mathrm{~h}$ temperatura: $750^{\circ} \mathrm{C}$

$950^{\circ} \mathrm{C}$

$1150^{\circ} \mathrm{C}$

Próbki po wyjęciu z pieca próżniowego wkładano do specjalnych pojemników próżniowych, w których je przechowywano i transportowano.

\section{Laboratoryjne testy lutowności}

Do przeprowadzenia testów zwilżania i rozpływności zastosowano specjalne urządzenie, którego zasadniczą częścią jest komora robocza z grzałką wolframową, regulatorem $i$ termoparą oraz wypoziomowany stolik, na którym umieszczane są próbki. Badania mogą być prowadzone w atmosferze gazów ochronnych, np. argonu, lub w próżni. Procesy zachodzące w komorze roboczej rejestruje kamera wyposażona w obiektyw przekazujący obraz do komputera. Przy użyciu specjalnego programu, służącego do analizy obrazów metalograficznych, mierzono kąty zwilżania z obu stron kropel i obliczano średnią arytmetyczną. Przykładowe kształty kropel ciekłego lutu podczas testu pokazano na rysunku 1, natomiast na rysunku 2 przedstawiono uzyskane $w$ ten sposób wartości kąta zwilżania $w$ funkcji temperatury.

Z rysunku 2 wynika, że im niższa temperatura uprzedniego wygrzewania Inconelu 718 , tym kąt zwilżania jest mniejszy. Najlepszy efekt uzyskano dla próbek wygrzewanych $w 750^{\circ} \mathrm{C}$. Zanik zwilzzalności jest obserwowany dla próbek wyżarzanych $w 1150^{\circ} \mathrm{C}$.

\section{Przemysłowe testy lutowności}

Do badań zastosowano lut $w$ postaci pasty oraz $w$ formie litej, co odzwierciedlało praktykę przemysłową. Luty pochodziły z tej samej partii we wszystkich przypadkach. Na powierzchnię podłoża nakładano 4 warstwy folii lutowniczej o średnicy $5 \mathrm{~mm}$ i grubości $0,05 \mathrm{~mm}$, które dla utrzymania właściwej pozycji mocowano wstępnie zgrzewaniem punktowym do podłoża. Pasta lutownicza była nakładana za pomocą programowanego aplikatora, który zapewniał nałożenie jednakowej ilości na każdą próbkę.

Tak przygotowane próbki poddano testom zwilżalności i rozpływności w warunkach odpowiadających standardowemu procesowi lutowania. Użyto tego samego pieca przemysłowego, który był wcześniej stosowany do wygrzewania próżniowego podłoży.

Widok kropel lutu na próbkach po testach lutowności przedstawiono na rysunku 3 . Zmierzono pola powierzchni rozpłynięcia lutu, a następnie wykonano szlify do badań metalograficznych. Na próbkach określono także kąt zwilżania i szerokość strefy dyfuzyjnej, której pomiar został wykonany jak na rysunku 4. Pomimo że zasięg dyfuzji po granicach ziarn jest znacznie większy, do oceny przyjęto zakres dyfuzji sieciowej, co odpowiada standardom lotniczym.

Wyniki pomiaru pola powierzchni po teście rozpływności oraz kąta zwilżania i wielkości strefy dyfuzji przedstawiono na rysunku 5.

Najlepszą zwilżalność w warunkach przemysłowych wykazują próbki wygrzewane uprzednio
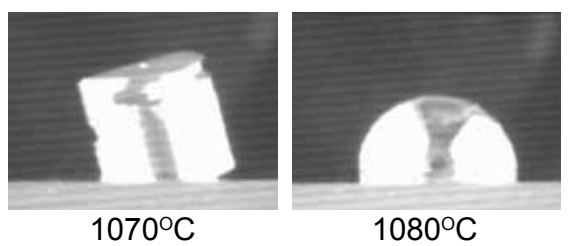

$1080^{\circ} \mathrm{C}$

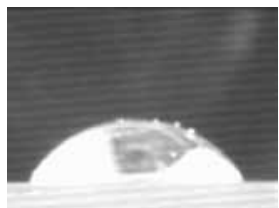

$1100^{\circ} \mathrm{C}$

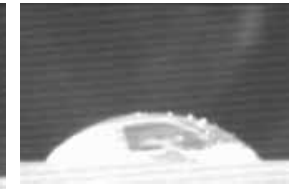

$1110^{\circ} \mathrm{C}$

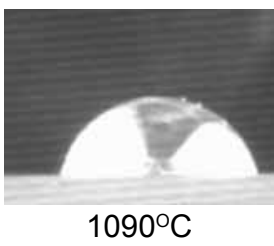

$1090^{\circ} \mathrm{C}$

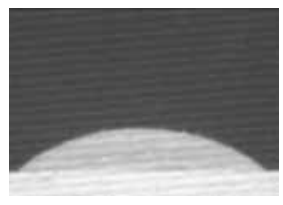

$1120^{\circ} \mathrm{C}$
Rys. 1. Krople lutu Palnicro 36 na powierzchni próbki Inconelu 718 wygrzewanego uprzednio $\mathrm{w}$ temp. $950^{\circ} \mathrm{C}$ przez $1 \mathrm{~h}$ pod ciśnieniem cząstkowym argonu $80 \mathrm{~Pa}$

Fig. 1. The drops of Palnicro 36 filler metal over the surface of Inconel 718 sample previously annealed at a temperature of $950^{\circ} \mathrm{C}$ for $1 \mathrm{~h}$ at a partial pressure of $80 \mathrm{~Pa}$ 


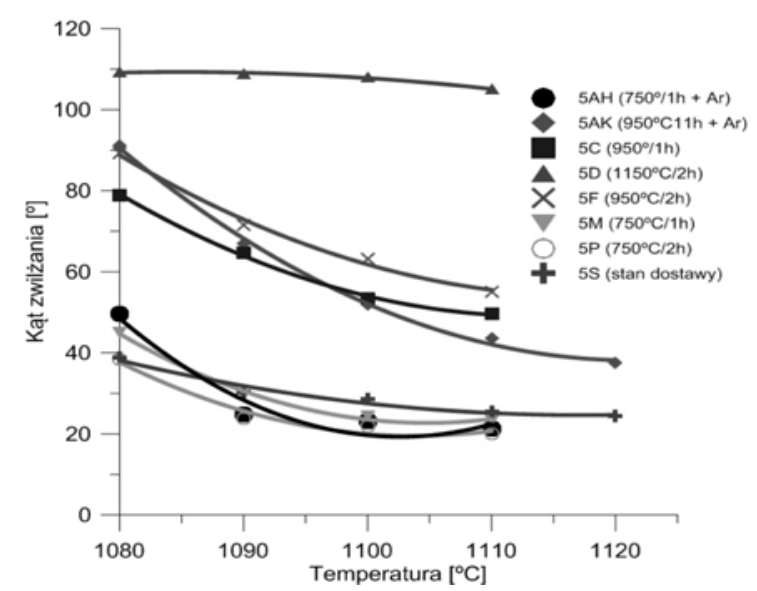

Rys. 2. Skrajne kąty zwilżania Inconelu 718 lutem Palnicro 36 w funkcji temperatury. Podłoża były uprzednio wyżarzane w warunkach obniżonego ciśnienia, próbka $5 \mathrm{~S}$ w stanie dostawy

Fig. 2. Extreme wetting angles of Inconel 718 with Palnicro 36 brazing filler metal as a function of a temperature. The substrates have been previously annealed under reduced pressure, sample $5 S$ as delivered

w temp. $750^{\circ} \mathrm{C}$ w czasie $1 \mathrm{~h}$ w próżni. Źle zwilżalna jest próbka wygrzewana w $1150^{\circ} \mathrm{C}$ w czasie $2 \mathrm{~h}$. Pozostałe próbki wykazują zbliżone zachowanie. Wielkość pola powierzchni rozpłynięcia kropli koreluje odwrotnie z kątem zwilżania. Różnice szerokości strefy dyfuzyjnej dla poszczególnych wariantów są nieznaczne.

\section{Badania metalograficzne złączy lutowanych}

Próbki uprzednio wygrzane w próżni oraz pod ciśnieniem cząstkowym argonu lutowano za pomocą lutu Palnicro 36. Każde złącze składało się z dwóch jednoimiennych płaskich próbek, które składano na zakładkę o szerokości $5 \mathrm{~mm}$ i stabilizowano przez zgrzewanie kuleczkami Cr-Niw celu zapewnienia właściwej szczeliny lutowniczej i zabezpieczenia przed przemieszczeniem. Lut w postaci pasty nakładano tylko $\mathrm{z}$ jednej strony zakładki. Widok zmontowanej próbki przedstawiono na rysunku 6.

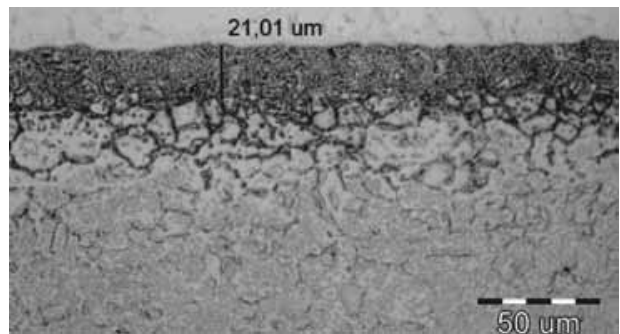

Rys. 4. Sposób pomiaru strefy dyfuzyjnej

Fig. 4. The method of diffusion zone measurement
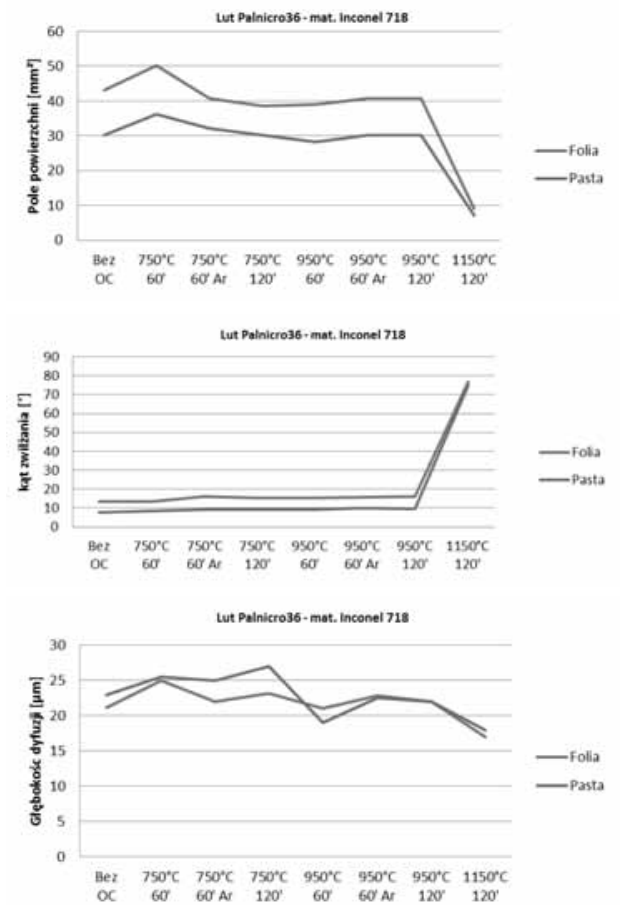

Rys. 5. Wpływ parametrów wcześniejszego wygrzewania podłoży Inconelu 718 w próżni na wielkość pola powierzchni rozpłynięcia lutu, kąta zwilżania i głębokości strefy dyfuzji. Lut Palnicro 36 w postaci folii oraz pasty lutowniczej

Fig. 5. The influence of prior annealing parameters of Inconel 718 substrates in a vacuum on the size of the spreading area, wetting angle and depth of the diffusion zone. The Palnicro 36 in the form of a foil and a brazing paste

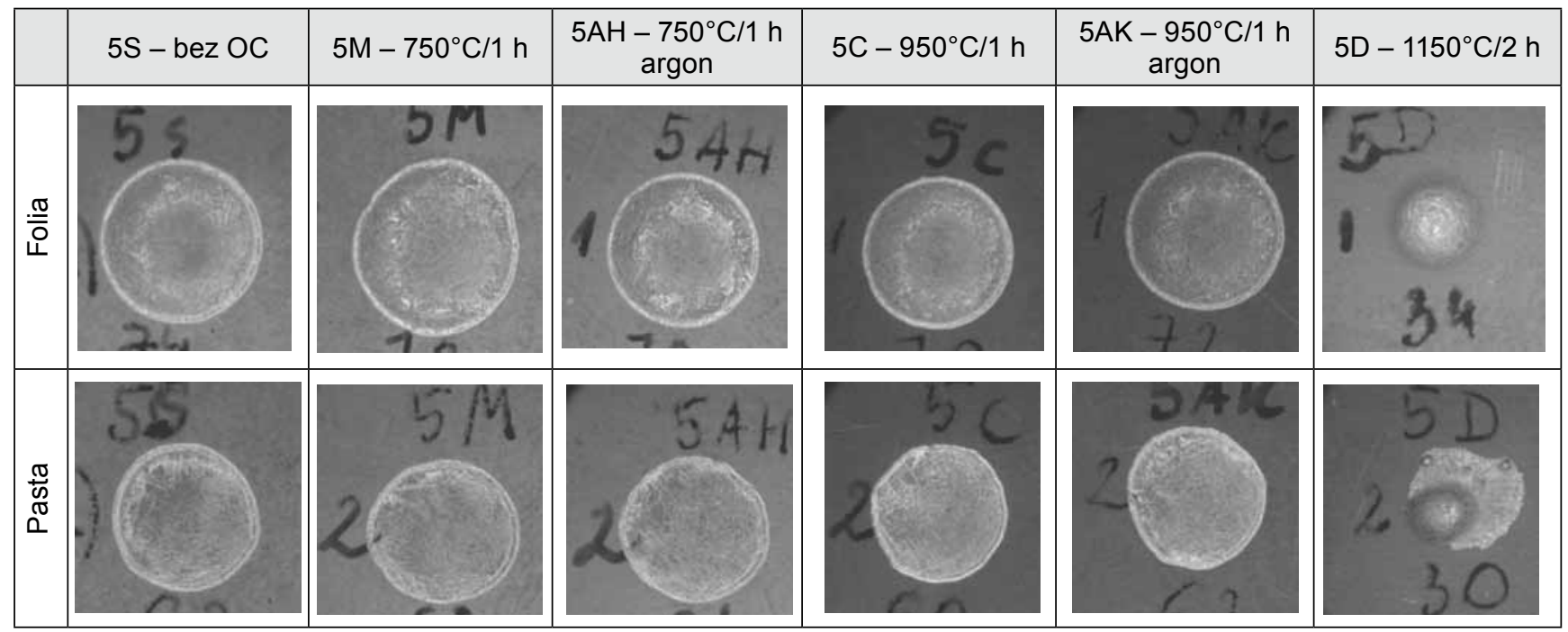

Rys. 3. Krople lutu Palnicro 36 na podłożach Inconelu 718 (widok z góry)

Fig. 3. The drops of Palnicro 36 brazing filler metal on the Inconel 718 substrate (view from above) 
a)

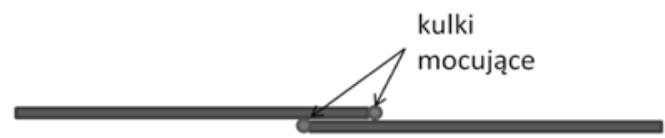

b)

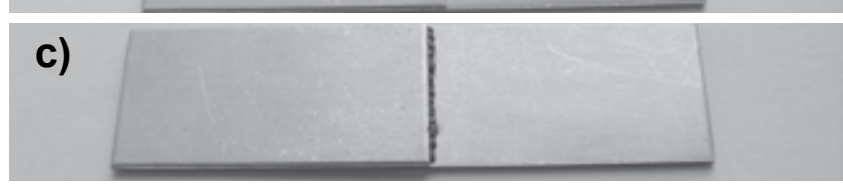

Rys. 6. Próbka do przemysłowych testów lutowania: a) przekrój poprzeczny, b) widok z góry po stabilizacji kulkami, c) widok z góry po nałożeniu pasty

Fig. 6. The sample used for industrial brazing tests: a) transverse cross-section, b) the view from above after stabilization with balls, c) the view from above after applying the paste
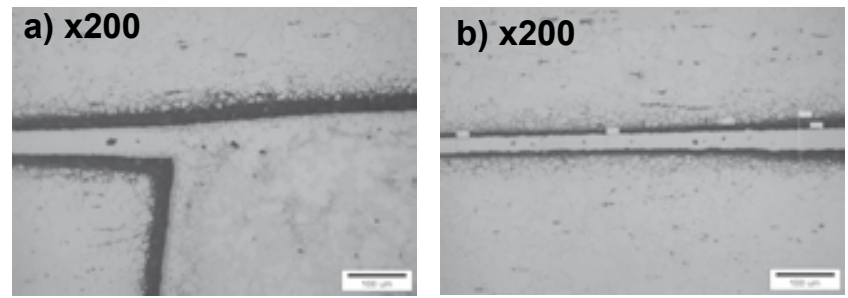

Rys. 7. Złącze lutowane Inconelu 718 bez uprzedniej obróbki cieplnej: a), b) dwa różne obszary

Fig. 7. The braze joint of Inconel 718 without the previous heat treatment: a), b) two different regions

Tak przygotowane komplety lutowano w piecu próżniowym. Otrzymane złącza poddano badaniom metalograficznym na mikroskopie świetlnym Olympus,

\section{Podsumowanie}

Zasadniczo, wraz ze wzrostem temperatury uprzedniego wygrzewania próżniowego lutowność Inconelu 718 lutem Palnicro 36 maleje. Najlepszą lutowność wykazują próbki wygrzewane w temp. $750^{\circ} \mathrm{C}$. Z wyjątkiem próbki wygrzewanej w temp. $1150^{\circ} \mathrm{C}$ w czasie $2 \mathrm{~h}$ wszystkie złącza charakteryzowały się wklęsłym meniskiem lutowiny.

\section{Literatura}

[1] Dul I.: Zastosowanie i przetwarzanie stopów Ni w przemyśle lotniczym, Przegląd Spawalnictwa No 7, 2009, 67-73.

[2] M. Schwartz: Brazing.Second Ed.,ASM International, 2003.

[3] R.D. Eng, E.J. Ryan, J. Doyle: Ni-based brazing with filler metals for aircraft gas turbine application, Welding J. 50, 1977, $15-21$.

[4] Sulcer Metco Braze Materials Guide. Standard and superalloy Filler Materials/Nickel Base, Issue April 2011.

[5] X. Wu, R.S. Chandel, M. Li, H.P. Seow, S. Wu: Induction brazing of Inconel 718 to Inconel $\mathrm{X}-750$ using Ni-Cr-Si-B amorphous foil, J. Material Processing Technology, 104, 2000, $34-43$.

[6] J. Christensen, K. Rorbo: Nickel Brazing Below $1025^{\circ} \mathrm{C}$ of Untreated Inconel 718. 5th International AWS Brazing Conference, Houston (IX) 1974

[7] Brazing Handbook, 4th Ed., AWS, Miami (FL), 1991.

[8] C.A. Blue, R.A. Blue, R.Y. Lin, J.F. Lei, W.D. Williams: Joining of Hastelloy $X$ to Inconel 718 using an infrared process. J. Mater. Proc. Technol. 58 (1996) 32-38.

[9] M.S. Yeh, T.H. Chuang: Effects of applied pressure on the brazing of superplastic Inconel 718 superalloy, Metall. Mater. Trans. A 28A, 1997, 1367-1376.
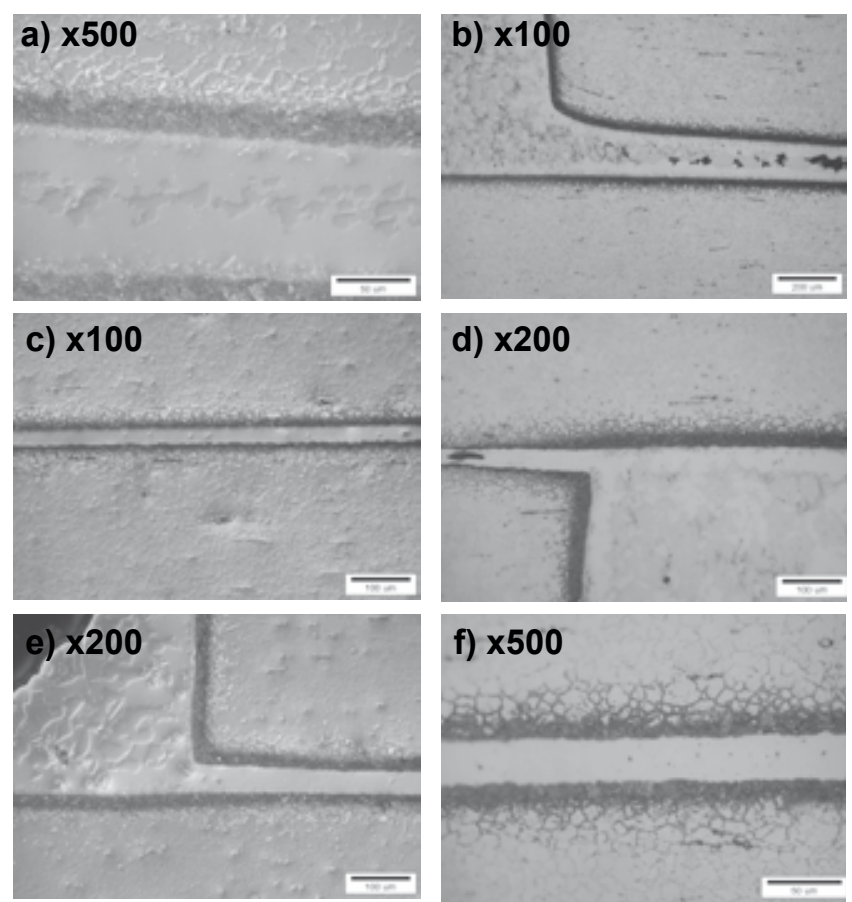

Rys. 8. Złącza lutowane Inconelu 718 wygrzewanego uprzednio w próżni w temp. $950^{\circ} \mathrm{C}$ w czasie $1 \mathrm{~h}(\mathrm{a}, \mathrm{b})$, oraz pod ciśnieniem cząstkowym Ar przez $1 \mathrm{~h}$ (c, d) i 2 h (e, f)

Fig. 8. The braze joint of Inconel 718 previously annealed in vacuum at a temp. of $950^{\circ} \mathrm{C}$ for $1 \mathrm{~h}(\mathrm{a}, \mathrm{b})$, for $1 \mathrm{~h}$ at a partial pressure of $\mathrm{Ar}$ (c, d) and for $2 \mathrm{~h}(\mathrm{e}, \mathrm{f})$

część zdjęć wykonano przy zastosowaniu pryzmatu Nomarskiego. Przykładowe struktury połączeń lutowanych przedstawiono na rysunkach 7 i 8.

Stwierdzono dobre wypełnienie szczeliny lutowniczej, ciągła granicę międzyfazową lut-podłoże oraz wyraźne strefy oddziaływania lutu z podłożem z wyjątkiem próbek Inconelu 718 wygrzewanego uprzednio w temp. $1150^{\circ} \mathrm{C}$.

Niedopuszczalne jest stosowanie wyżarzania próżniowego Inconelu 718 przed lutowaniem w temperaturze powyżej $1100^{\circ} \mathrm{C}$, gdyż materiał ten wykazuje wówczas zmiany w warstwie wierzchniej powodujące brak lutowności.

[10] MAArafin, M. Medraj, D.P.Turner, P.Bocher: Transient liquid phase bonding of Inconel 718 and Inconel 625 with BNi2: Modeling and experimental investigations. Mat. Sci. Eng. A447, 2007, 125-133.

[11] High Temp. Metals, Technical Data. www.hightempmetals.com

[12] Roach T.A.: Alloy 718 Fasteners, versality and reliability for aerospace design, Superalloy 718-Metallurgy and Applications, TMS 1989, 381-389.

[13] Ghonem H, Zheng D.: Charactrization of enviroment-dependent fatigue crack growth in alloy 718 at $650 \mathrm{C}$, Superalloys 718,625 and Various Derivatives, TMS, 1991, 477-490.

[14] Ming G., Dwyer D.J., Wei R.P.: Chemical and microstructural aspects of creep crack growth in Inconel 718 alloy, Superalloys 718, 625, 706 and Various Derivatives, TMS, 1994, 581-592.

[15] Sundararaman M., Mukhopadhyay P., Banerjee S.: Carbide precipitation in nickiel base superalloys 718 and 625 and their effect on mechanical properties, Superalloys $718,625,706$ and Various Derivatives, TMS, 1997, 367-378.

[16] Palnicro 36. Katalog Morgan Advanced Materials, 2009.

[17] Winiowski A.: Lutowność w lutowaniu twardym - definicje i przykłady jej badania, Przegląd Spawalnictwa, No 9, 2010, 58-62. 